\title{
COMMUNICATIONS
}

\section{ANASTOMOSES BETWEEN THE RETINAL AND CILIARY ARTERIAL CIRCULATIONS*}

\author{
BY \\ KENNETH C. WYBAR \\ Department of Pathology, Institute of Ophthalmology, University of London
}

\section{Aim AND Scope of Present Study}

THIS investigation is concerned with an examination of the arteries in and around the optic nerve with particular reference to the hypothesis that there may be anastomoses between the retinal and ciliary arterial circulationsa hypothesis which is important in a discussion of the pathological events which may follow occlusion of the central retinal artery. All the observations have been determined by an examination of casts of the ocular circulation prepared by the intravascular injection of Neoprene latex according to the method devised by Ashton (1951, 1952). Some of the observations have been reported in a preliminary communicaiion (Wybar, 1954b).

Previous Descriptions of Uveo-Retinal Arterial anastomoses

There is no evidence that uveo-retinal vascular anastomoses occur within the normal globe, and, indeed, it is known that Bruch's membrane, in its healthy intact state, forms an impenetrable barrier to the passage of blood vessels, so that, except in certain pathological conditions when the continuity of Bruch's membrane is disturbed (as in a case described by Michaelson, 1951), there are no such anastomoses. This was verified during a recent investigation of the choroidal circulation, by an examination of Neoprene casts of the ocular vessels (Wybar, 1954a), and no chorio-retinal anastomoses were found even in the region of the ora serrata which has been suggested as a possible site of anastomosis from time to time. Attention has been concentrated, therefore, on the region of the optic nerve, particularly near the optic nervehead where the ciliary and retinal vessels pass close to one another as they enter the globe.

Anastomoses between, first, the arterial circle of Zinn and the central retinal artery, and, secondly, the choroidal arteries and the central retinal artery, have been postulated in the region of the optic nervehead by Nettleship (1876), Leber (1903), and Coats (1905). Nettleship (1876) considered that the first of these anastomoses is purely capillary, but that the second is more direct. On the other hand, Leber (1903) regarded both anastomoses as capillary in type, although it appears that he was not too happy about this conclusion because he qualified it by saying that the whole matter merited a further and more detailed investigation. In the diagram with which he illustrated his findings on the ocular circulation, the anastomosis is shown as a direct one, and it is somewhat unfortunate that this

*Received for publication August 18, 1955. 
diagram should have been reproduced in so many subsequent papers without due regard to Leber's remarks in the text regarding the nature of the anastomosis.

Coats (1905) shared Leber's view that both anastomoses are capillary in nature, although he believed that, after occlusion of the central retinal artery, the fine capillary anastomoses may dilate sufficiently to become visible ophthalmoscopically as fine arterial networks around the optic disc. Coats substantiated his viewpoint by the hypothesis that the haemorrhages which he found in the peripapillary part of the retina in certain of these cases were due to the rupture of the fine anastomotic vessels during the process of dilatation. Gonin (1905) also described similar anastomotic channels in cases of central retinal arterial block-vessels which emerged from the disc margin and passed into the retina to join the attenuated retinal arteries. The retinal arteries lost their thread-like appearance distal to this point of union.

Coats (1913b) showed that, after total occlusion of the central retinal artery, an area of light perception may remain around the blind spot, particularly on its temporal aspect. It is possible, of course, for the retina immediately adjacent to the optic disc to derive a certain amount of nourishment from the normal capillaries of the optic nervehead, but Coats considered that the area of sparing was too great for such an explanation and postulated that the retention of light perception in the peripapillary field was further evidence for the existence of uveo-retinal arterial anastomoses. Some years earlier, de Schweinitz and Holloway (1908) had put forward a similar hypothesis to explain the retention of light perception around the blind spot in cases of occlusion of the central retinal artery.

It is important to distinguish clearly these uveo-retinal arterial anastomoses from the so-called cilio-retinal arteries which have been described by many observers (Nettleship, 1877; Randall, 1887; etc). Uveo-retinal arterial anastomoses constitute a direct link between the ciliary arterial circulation and the main stem of the retinal artery, whereas cilio-retinal arteries are small retinal arteries which occur in a certain number of normal eyes ( 23 per cent. according to Lang and Barrett, 1888 ) and are derived, not from the retinal circulation, but from the ciliary circulation through the circle of Zinn. It follows, therefore, that in the event of a sudden blockage of the central retinal artery the blood continues to flow in a cilio-retinal artery although it ceases to circulate in the main retinal arteries. However, a cilio-retinal artery is a true end-artery which supplies only a localized segment of the retina, commonly on the temporal aspect of the optic disc, and its presence is of no avail in the restoration of the circulation within the main retinal arteries. This is in contrast to a uveo-retinal arterial anastomosis which, if present on the distal side of the arterial occlusion, provides an alternative pathway for the passage of blood into the whole retinal circulation, despite the continuance of the occluding process in the central artery of the retina.

A further type of anastomosis which must be distinguished from a uveo-retinal arterial anastomosis, is the so-called inter-retinal arterial anastomosis which occurs as a rare event after occlusion of a single branch of the retinal artery within the retina. Coats (1913c) described such a case, in which a collateral artery linked a patent retinal arterial branch to the occluded one with consequent restoration of circulation in the affected branch distal to the point of union. An inter-retinal arterial anastomosis is not relevant, however, to a discussion of the pathological events which may follow occlusion of the main stem of the central retinal artery. 
In addition to the importance of uveo-retinal arterial anastomoses from a pathological point of view, evidence has been put forward recently by Sautter and Seitz (1952) that such anastomoses may also have a physiological significance. In an experimental investigation on the rabbit, Sautter and Seitz found, under normal conditions, that a vital dye injected intravenously passed along the retinal artery to the lamina cribrosa where it was diverted to the arterial circle of Zinn within the sclera; but, after the use of a sympatholytic agent, the dye passed along the retinal artery into the retina without being diverted to the circle of Zinn. This was regarded as evidence for the existence of an anastomosis between the central retinal artery and the circle of Zinn, at the level of the lamina cribrosa, under vegetative control through the mediation of a glomus apparatus at the point of origin of the anastomotic channel from the central retinal artery.

Sautter and Seitz regarded the flow along the anastomotic channel as a unidirectional one, so that the blood passes only from the central retinal artery to the circle of Zinn and never in the reverse direction. They described the existence of two arterial rings within the circle of Zinn: a lower one formed by branches from two or three short posterior ciliary arteries, and an upper one connected to the lower ring from which it obtains its blood by a process of suction. Both rings are connected to the central retinal artery by anastomotic branches. According to Sautter and Seitz these anastomotic channels divert blood from the retinal artery to the circle of Zinn and act as a mechanism which protects the retina from an excess of blood; the arterial rings, by virtue of their free connexions with the choroid and with the arterial plexus of the pia mater surrounding the optic nervehead, are less likely to be embarrassed by an additional volume of blood than the retinal arteries which are functional end-arteries.

This is an interesting study and it gives the arterial circle of Zinn a hitherto unknown physiological significance, but it does not provide any information regarding the exact site and nature of the uveo-retinal anastomotic channels. The existence of such channels has been inferred from the results of the experiment rather than from anatomical observation. In fact Sautter and Seitz restated the original hypothesis of Leber (1903) that the anastomoses are only of capillary dimensions, and it is difficult to relate the physiological implications of their experimental work to such a poorly-developed anastomosis. Parsons (1906), who also agreed with Leber's findings of a capillary anastomosis, considered that this type of anastomosis is of little or no physiological significance. Furthermore, it is uncertain to what extent observations on the rabbit may be related to the human eye with its obvious structural and physiological differences.

It is interesting to note that Moffat (1952) described an analogous type of glomus apparatus in the dog. In this animal the retinal artery is a branch of a ciliary artery and, at its potnt of origin, Moffat found a sub-endothelial cushion of smooth muscle within the circular muscle of the ciliary artery, which he believed acts as a regulator of the blood passing into the retina, so that the retinal blood flow may be maintained even when the ciliary circulation is diminished.

There is, therefore, a considerable amount of anatomical, pathological, and physiological evidence to suggest that there are uveo-retinal arterial anastomoses within the optic nervehead, but there is also some evidence which conflicts with such a concept.

Magitot (1908), Beauvieux and Ristitch (1924), and Behr (1935) failed to demon- 
strate any anastomosis between the ciliary and retinal arteries, and, furthermore, they all considered that such anastomoses are impossible on the grounds that no branches arise from the central retinal artery within the optic nerve tissues. At one time the view that the central retinal artery continued through the optic nerve without giving off any branches was supported by Wolff $(1938,1939)$, but later Wolff $(1948)$ showed, in a histological preparation of the optic nerve that a small branch arose from the central artery in the region of the lamina cribrosa. He did not demonstrate any anastomosis of this arterial branch with any other artery in the optic nervehead, but he considered it to be presumptive evidence of at least a capillary anastomosis between the retinal and ciliary circulations.

Bignell (1952) described branches which emerged from the central retinal artery just behind the lamina cribrosa but which came to an end within that part of the optic nerve without forming any anastomosis with the other arteries in the optic nervehead derived from the arterial circle of Zinn. Branches of the central retinal artery in the laminar part of the optic nerve were also shown by François and Neetens (1954), but the branches were considered to pass directly to the retina without taking part in any anastomosis. In this way all the branches of the central retinal artery, whether arising within the optic nerve or at the optic nervehead, were regarded as strictly terminal arteries to the retina. In a later communication, François, Neetens, and Collette (1955) found a complete absence of any branches from the intraneural part of the central retinal artery.

François and Neetens (1954), however, found another artery-the central optic nerve artery-which arose from the ophthalmic artery as a separate branch, accompanied the central retinal artery into the optic nerve, and then divided, first, into an anterior branch passing forwards to the lamina cribrosa in company with the central retinal artery, and, secondly, into a posterior branch passing backwards towards the optic foramen in the axial part of the optic nerve. They considered that the central optic nerve artery is nutritive to the deeper parts of the optic nerve, and that the anterior branch forms an anastomosis with other arterial branches in the laminar part of the optic nerve derived from the ciliary circulation. However, it is not possible to restore the retinal circulation after occlusion of the central retinal artery by means of such an anastomosis, and, therefore, it is not relevant to the study of anastomoses between the main retinal and ciliary circulations.

The central optic nerve artery would appear to be analogous to the collateral branch of the central retinal artery described by Beauvieux and Ristitch (1924), Behr (1935), and Wolff (1948). These observers found a collateral artery which arose from the central retinal artery within the orbit, accompanied the central retinal artery into the optic nerve, and then divided into an anterior branch running forwards in the axial part of the optic nerve to the lamina cribrosa, and a posterior branch running backwards in the axial part of the optic nerve towards the region of the optic foramen. They did not consider, however, that any anastomosis was formed between the anterior collateral artery and any arterial branches of the ciliary circulation within the optic nervehead, and in this respect differed from François and Neetens.

It is apparent, therefore, that there is doubt not only as to the exact situation and size of arterial uveo-retinal anastomoses, but even as to their very existence; in view of this uncertainty it was decided to investigate the whole arterial pattern in and around the optic nervehead. 


\section{Present InVestigation}

Material.-Seventeen human eyes, which were free, as far as could be ascertained, from any local ocular disease or from any gross change of a systemic nature, were removed at post mortem together with their associated orbital structures through an intracranial approach.

Technique.-After thorough irrigation of the ocular vessels with water by way of the ophthalmic artery and their injection with Neoprene, according to the method of Ashton (1952), the eyes in their fresh state were immersed in a saturated solution of pepsin in $\mathrm{N} / 10$ hydrochloric acid for 7 to 14 days at $37^{\circ} \mathrm{C}$., and then in a saturated solution of trypsin in 1 per cent. sodium bicarbonate at the same temperature.

To accelerate the process of digestion, most of the extra-ocular tissues were removed at the completion of the Neoprene injection, great care being taken to prevent any disturbance of the vessels in and around the optic nerve. Neoprene is not susceptible to the action of digestive ferments, so that a complete cast of the ocular vessels may be obtained, but it was found to be advantageous to stop the digestive process before it was quite complete, otherwise, through the loss of all supporting tissues, it was extremely difficult to identify the various vessel groups within the tangled network of Neoprene-injected vessels.

Each partially digested cast was placed in a large petri dish which contained a thin layer of black paraffin wax, and enough water was poured onto the wax to cover the cast completely. The vessel groups were then identified and, where necessary, pinned in position to the paraffin wax. (Fine glass pins were used in preference to steel ones, because the latter caused contamination of the casts with rust particles after a few days under water.) The fimnants of the ocular tissues were carefully removed to complete the exposure of the Neoprene cast. It was found that the optic nerve offered most resistance to the action of the digestive ferments, and, even in well-digested specimens, it was necessary to remove some of the nerve tissue by dissection. This was not a difficult procedure, because the nerve became friable and fragments were removed piece by piece without disturbing the Neopreneinjected vessels in and around it.

The Neoprene cast was then subjected to a detailed dissection under water using two pairs of fine watchmakers' forceps and a pair of fine spring scissors. The dissection was viewed through a wide-field stereoscopic microscope with direct illumination from one or two high-power low-voltage filament lamps, and, in order to expose the fine vessels within the optic nervehead, it was necessary, after removal of many of the surrounding vessels, to complete the dissection under fairly high magnification.

Findings.-Examination of the Neoprene casts of the ocular vessels of the seventeen eyes revealed many details regarding the nature of uveo-retinal arterial anastomoses. It is important to remember, however, that the findings are the result of the pooled data obtained from an examination of all the eyes, and that no attempt is made to state how often certain features occurred throughout the series. A complete cast of the ocular circulation presents a 
dense mass of vessels (Fig. 1), particularly in the region of the optic nervehead (Fig. 2) wherein lay the main objective of this study, and it is apparent that in order to expose a particular area many vessels in the surrounding fields had to be discarded. Each cast was approached, therefore, in a special way to demonstrate a definite aspect of the circulation, and as a result certain other features of interest had to be sacrificed.

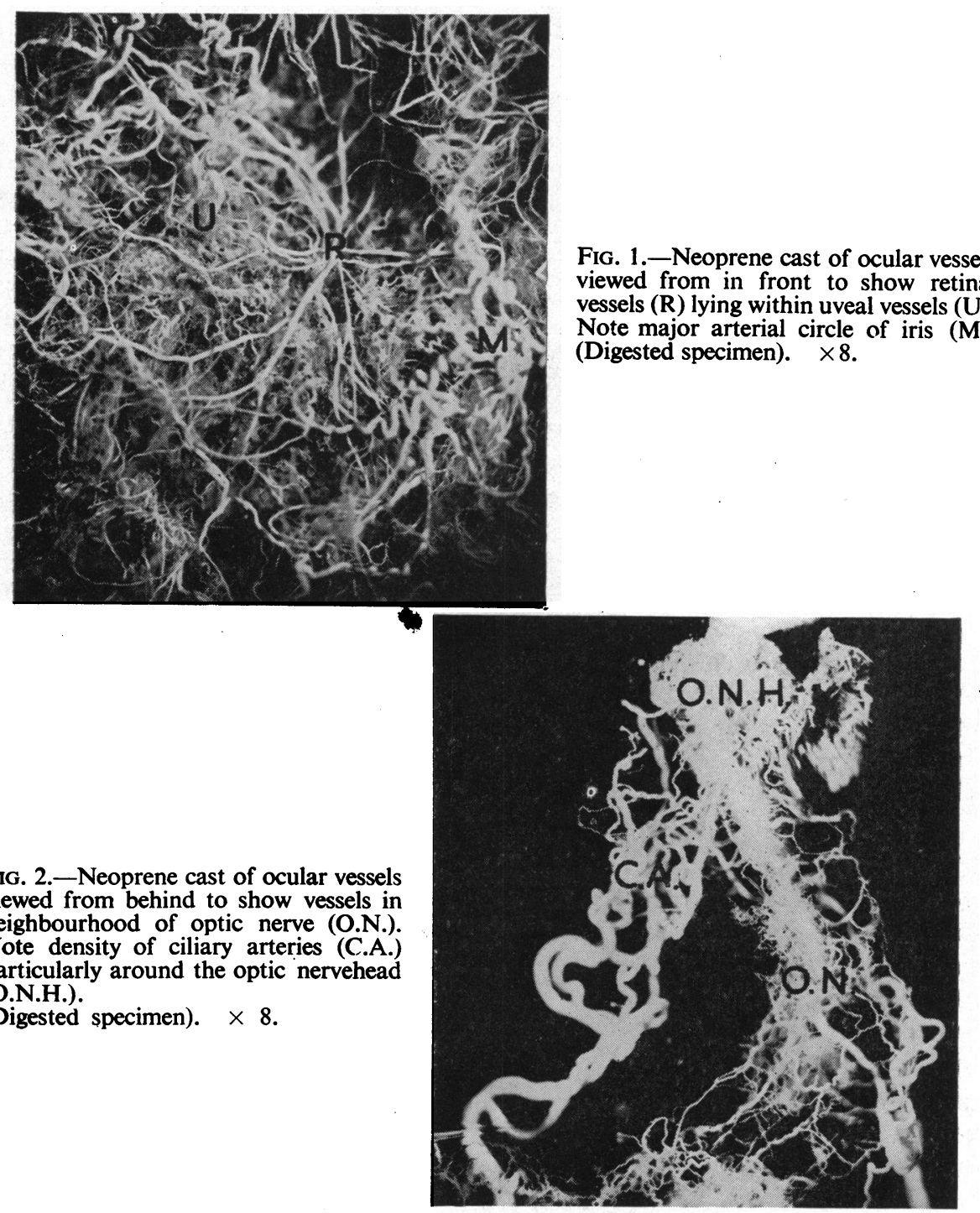

The following features were determined in an examination of the dissected Neoprene casts:

(a) Central Retinal Artery.-The central retinal artery arises as one of the first branches of the ophthalmic artery in the orbit either alone or in common with one

Fig. 2.-Neoprene cast of ocular vessels Note density of ciliary arteries (C.A.) particularly around the optic nervehead (O.N.H.).

(Digested specimen). $\times 8$. 


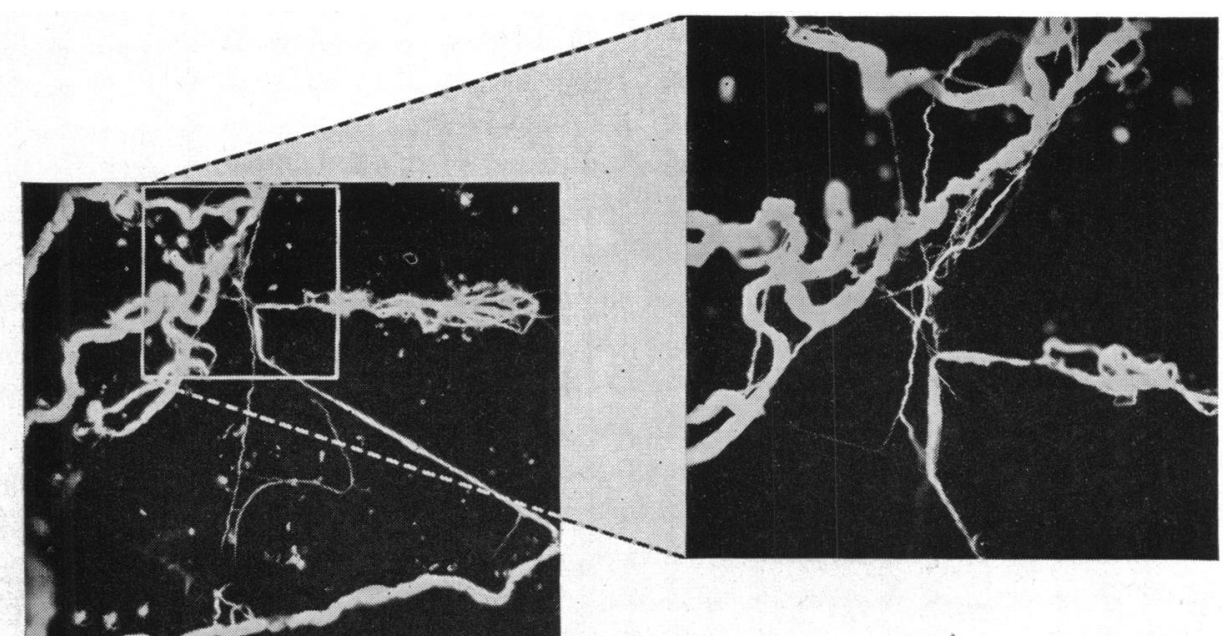

FIG. 3.-Neoprene cast of ocular vessels to show:

(i) Branches from central retinal artery, before entry into optic nerve, to arterial plexus of pia mater.

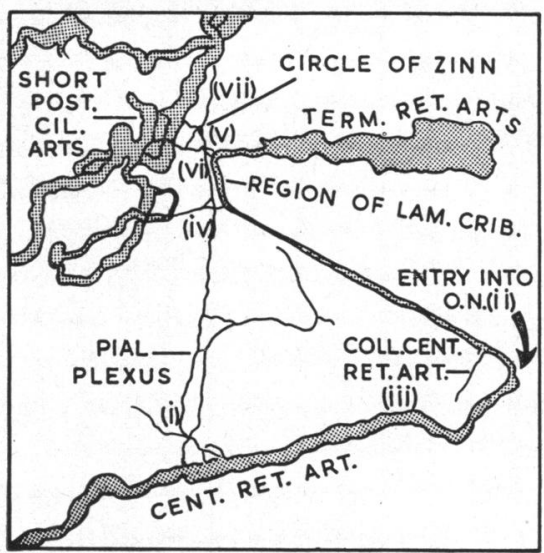

(ii) Narrowing of central retinal artery at entry into optic nerve.

(iii) Collateral central retinal artery.

(iv) Anastomosis between intraneural part of central retinal artery and arterial plexus of pia mater.

(v) Anastomoses between central retinal artery and circle of Zinn at lamina cribrosa.

(vi) Anastomosis between circle of Zinn and arterial plexus of pia mater.

(vii) Branches from posterior ciliary arteries to circle of Zinn and to arterial plexus of pia mater.

(Digested and dissected specimen). $\quad \times 6$ and $\times 15$.

of the two long posterior ciliary arteries. It runs below the optic nerve until it reaches about $15 \mathrm{~mm}$. from the globe where it turns upwards at $90^{\circ}$ to penetrate the optic nerve. In many casts there is a marked reduction in the calibre of the central retinal artery at the point where it enters the optic nerve (Figs 3, 4, 8). It is not felt, however, that any definite conclusion can be drawn from this regarding the calibre of the artery in life, because it is possible that this variation may merely result from the injection technique. Neoprene is injected into the ophthalmic artery under pressure, and it is natural that the central retinal artery should expand more where it is unsupported (as in the orbit) than where it lies within a dense mass of tissue (as in the optic nerve). After its entry into the nerve the artery passes to the centre of the nerve, where it turns forwards at $90^{\circ}$ to travel along the axial part of the nerve to the optic disc where it divides into its definitive retinal branches.

The central retinal artery during its intra-orbital and intraneural course gives the following branches: 

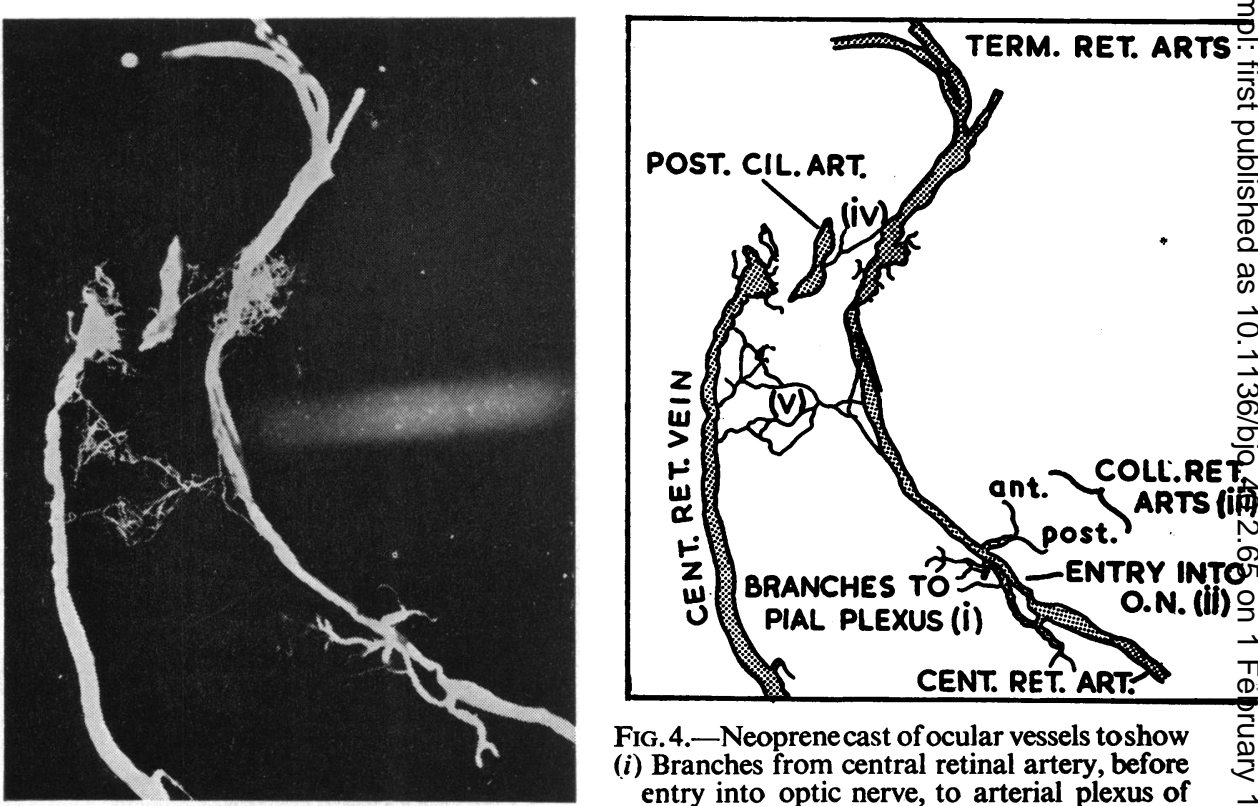

FIG. 4.-Neoprene cast of ocular vessels toshow

(i) Branches from central retinal artery, before entry into optic nerve, to arterial plexus of pia mater.

(ii) Narrowing of central retinal artery at entry into optic nerve.

(iii) Anterior and posterior collateral central retinal arteries.

(iv) Branches from central retinal artery at lamina cribrosa, showing capillary anastomosis with short posterior ciliary artery.

(v) Branches from central retinal vein at lamina cribrosa showing capillary anastomosis with central retinal artery.

(Digested and dissected specimen). $\times 9$.
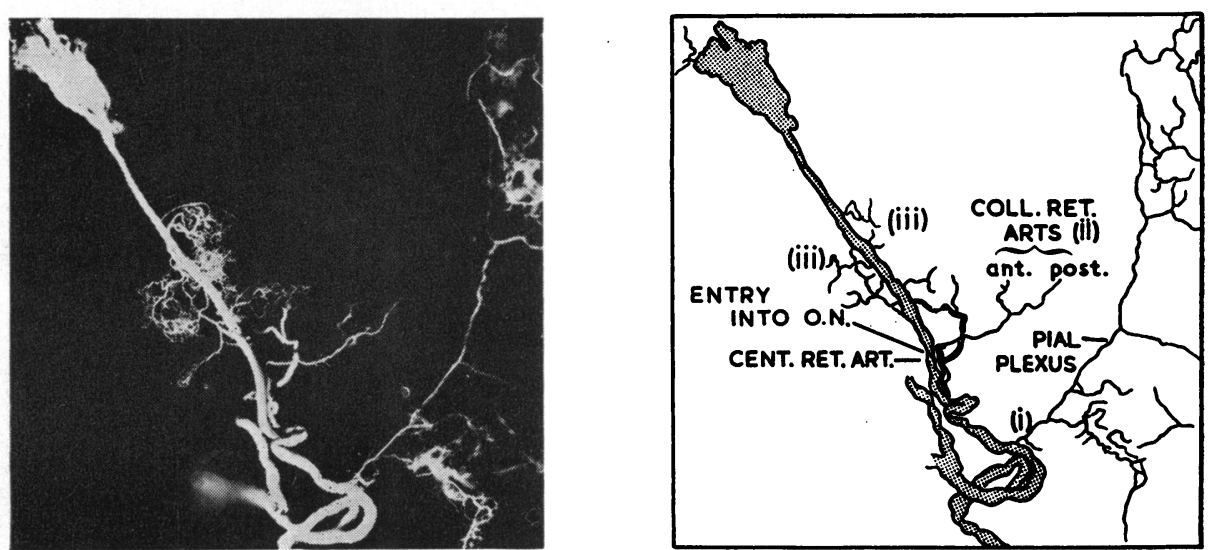

FIG. 5.-Neoprene cast of ocular vessels to show:

(i) Branches from central retinal artery, before entry into optic nerve, to arterial plexus of pia mater.

(ii) Anterior and posterior collateral central retinal arteries.

(iii) Branches from intraneural part of central retinal artery.

(Digested and dissected specimen). $\times 6$.

(i) Branches which arise from the central retinal artery at any point between the origin of the artery from the ophthalmic artery and the entry of the artery into the optic nerve, and which contribute to the arterial plexus of the pia mater which surrounds the optic nerve within the orbit (Figs 3, 4, 5, 6, 8, 9).

(ii) Branches which arise from the central retinal artery at the point where the 

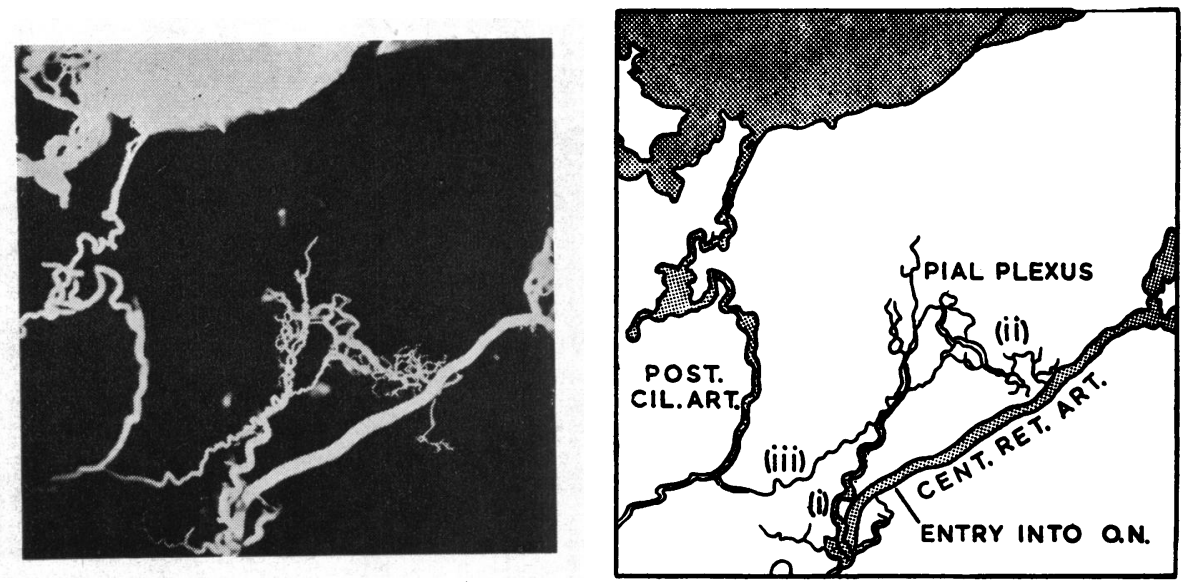

Fig. 6.-Neoprene cast of ocular vessels to show:

(i) Branches from central retinal artery, before entry into optic nerve, to arterial plexus of pia mater.

(ii) Anastomoses between intraneural part of central retinal artery and arterial plexus of pia mater.

(iii) Branch from posterior ciliary artery to arterial plexus of pia mater. (Digested and dissected specimen). $\times 6$.
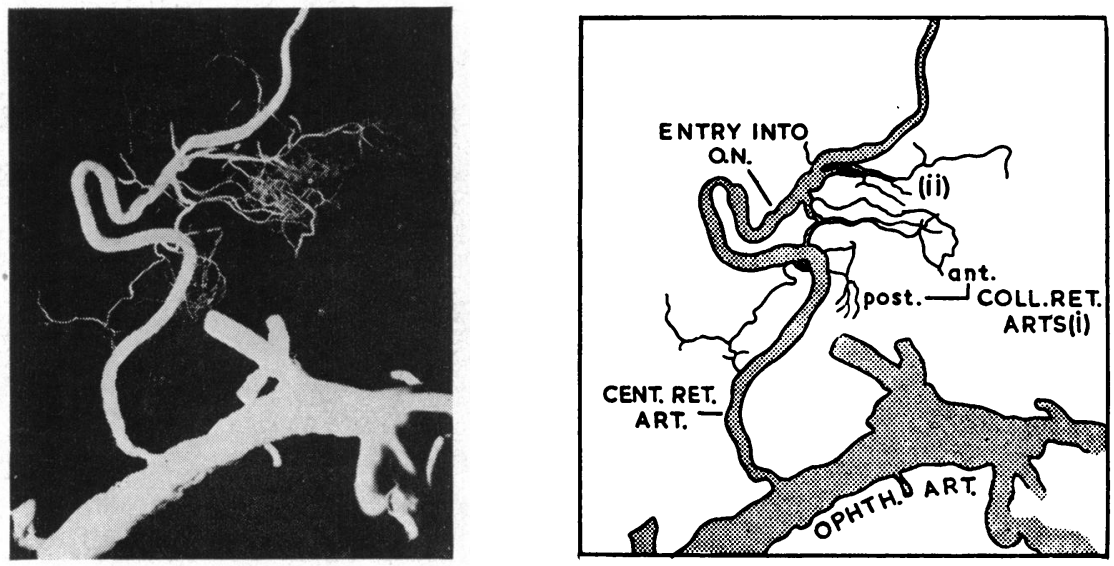

FIG. 7.-Neoprene cast of ocular vessels to show:

(i) Anterior and posterior collateral central retinal arteries.

(ii) Branches from intraneural part of central retinal artery. (Digested and dissected specimen). $\times 6$.

artery pierces the optic nerve to pass to its centre (Figs 3, 4, 5, 7). There are two such branches and they may arise separately or by a common trunk. One of the arteries passes forwards, and the other passes backwards in the axial part of the optic nerve, thus forming the anterior and posterior collateral central retinal arteries, although in the casts examined these branches were not traced along the whole length of their described course.

(iii) Branches which arise from the central retinal artery during its course within the optic nerve. Some of these appear to terminate within the tissues of the optic nerve (Figs 5 and 8), but others form anastomoses with branches from the arterial plexus of the pia mater (Figs 3, 6, 8, 9). Many branches are given off in the region of the lamina cribrosa and, although some of them end within the tissues of the optic nervehead, other laminar branches form anastomoses with the laminar branches from the 


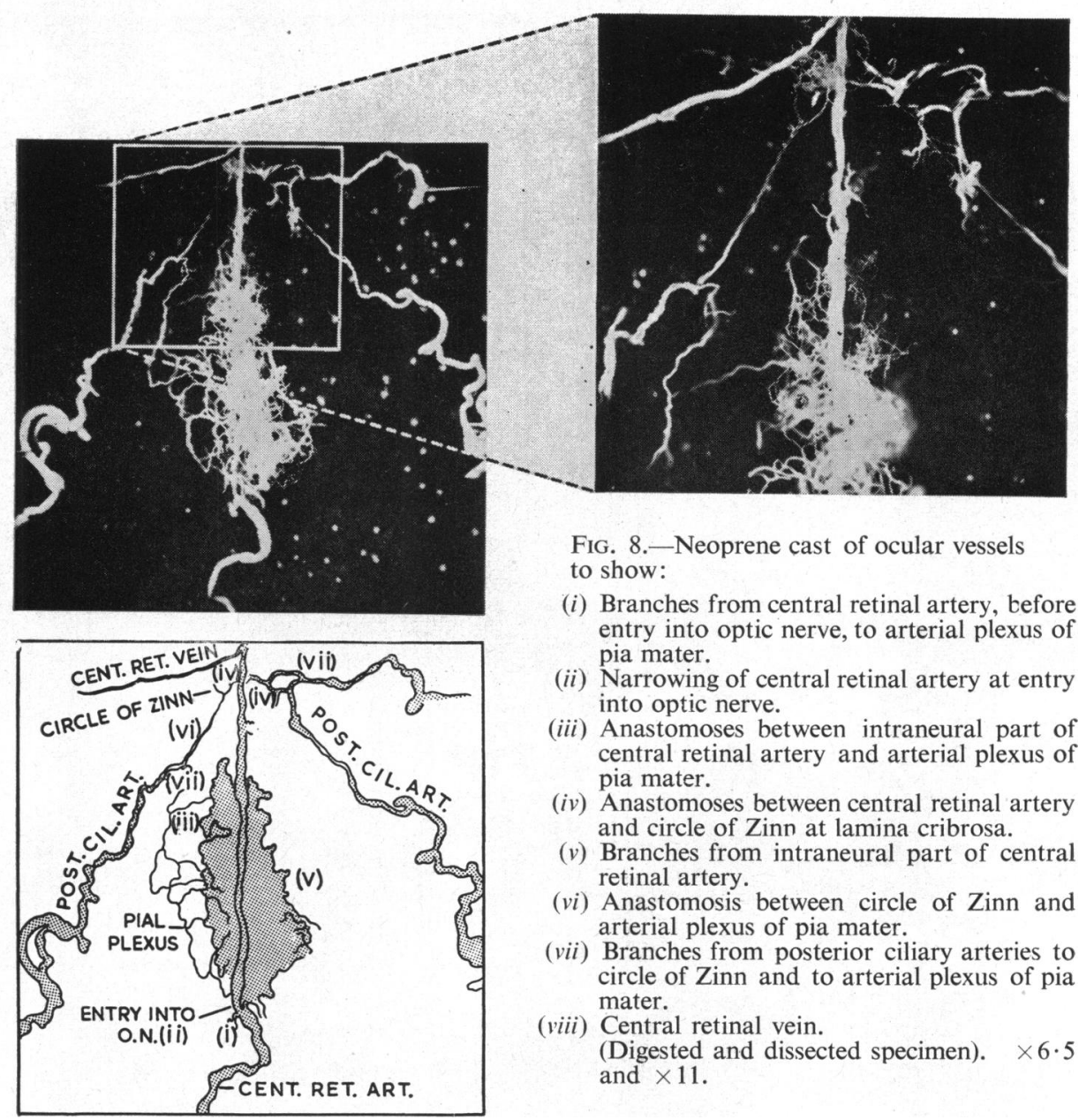

ciliary arteries (Figs 3, 4, 8,9). These latter branches are derived to a large extent from the intrascleral arterial circle of Zinn, so that the anastomosis is primarily with the circle of Zinn (Figs 3 and 8).

(b) Arterial Plexus of Pia Mater of Optic Nerve.-The arterial plexus of the pia mater, which forms a dense network of vessels surrounding the optic nerve, is made up from the following three sources:

(i) The short posterior ciliary arteries, which send many branches to the pial plexus (Figs 3, 6, 8, 9).

(ii) The central retinal artery, which sends branches to the plexus before the entry of the artery into the optic nerve (Figs 3, 4, 5, 6, 8, 9).

(iii) The circle of Zinn which sends branches backwards to the plexus (Figs 3 and 8).

From the arterial plexus in the pia mater many branches pass into the optic nerve; some of these terminate within the nerve tissue but others anastomose with branches from the central retinal artery (Figs 3, 6, 8, 9).

(c) Arterial Circle of Zinn.-This lies within the sclera surrounding the optic 

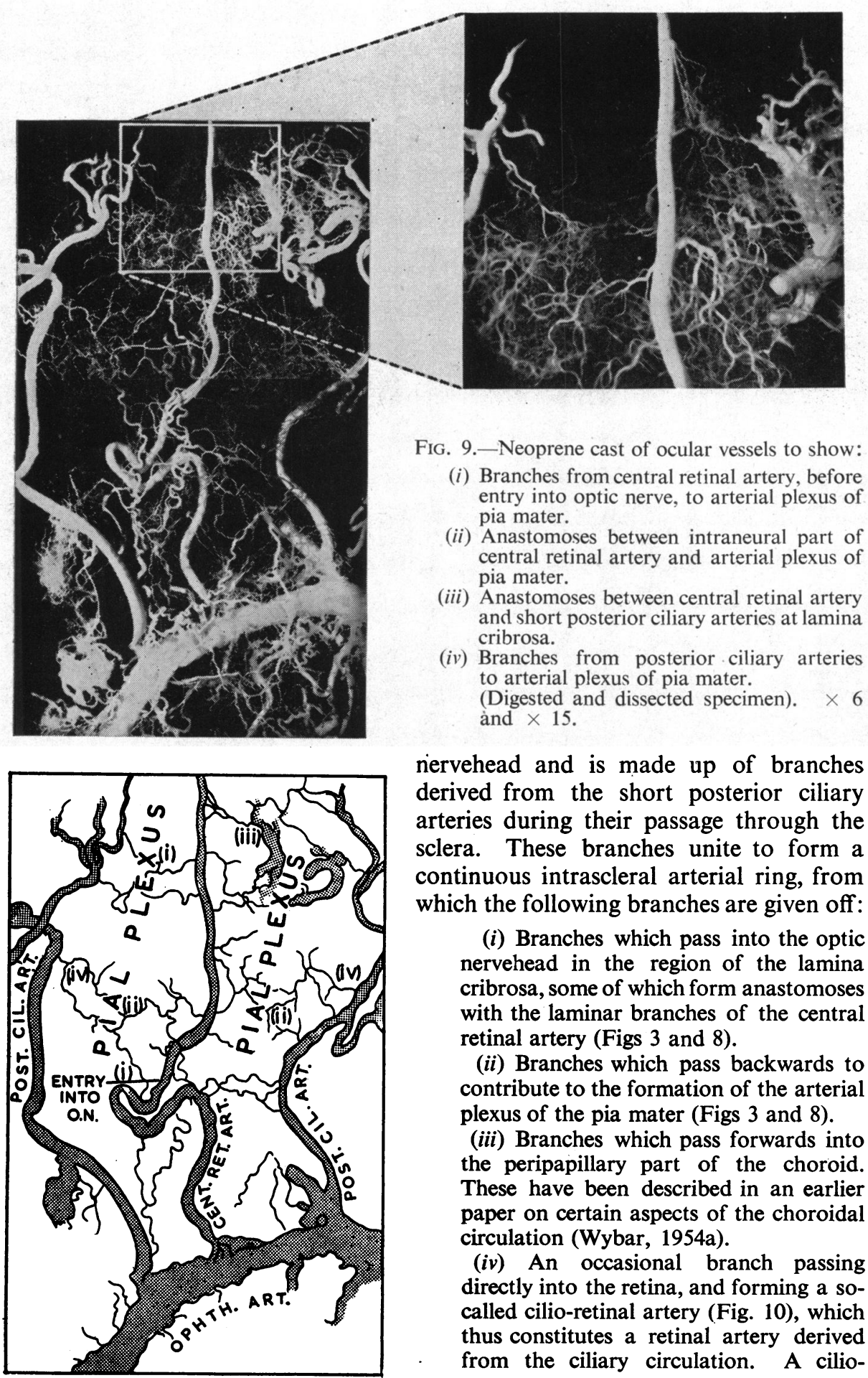

nervehead and is made up of branches derived from the short posterior ciliary arteries during their passage through the sclera. These branches unite to form a continuous intrascleral arterial ring, from which the following branches are given off:

(i) Branches which pass into the optic nervehead in the region of the lamina cribrosa, some of which form anastomoses with the laminar branches of the central retinal artery (Figs 3 and 8 ).

(ii) Branches which pass backwards to contribute to the formation of the arterial plexus of the pia mater (Figs 3 and 8).

(iii) Branches which pass forwards into the peripapillary part of the choroid. These have been described in an earlier paper on certain aspects of the choroidal circulation (Wybar, 1954a).

(iv) An occasional branch passing directly into the retina, and forming a socalled cilio-retinal artery (Fig. 10), which thus constitutes a retinal artery derived from the ciliary circulation. A cilio- 

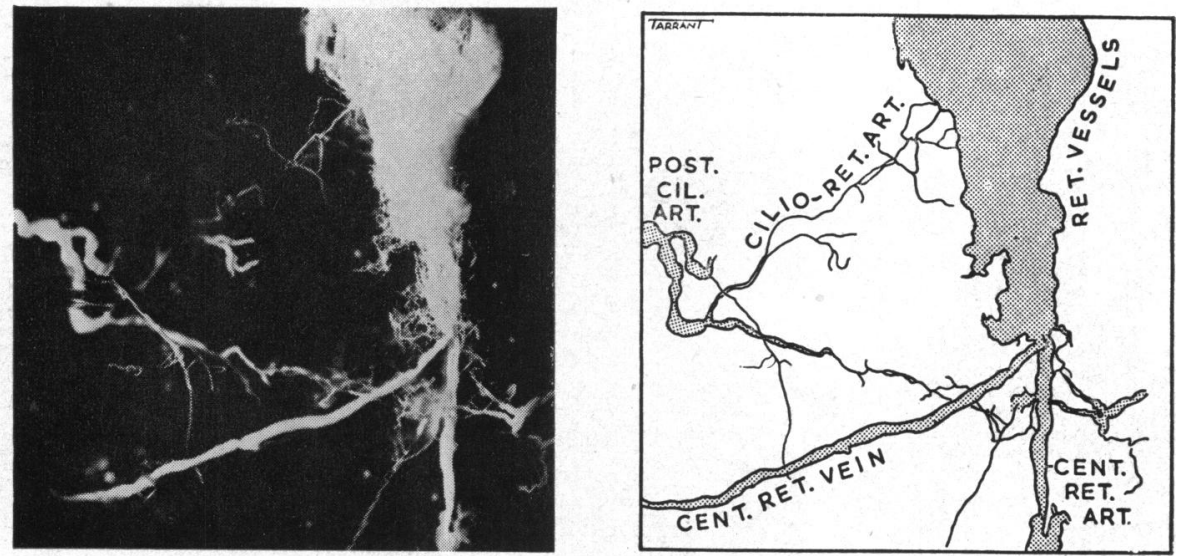

Fig. 10.-Neoprene cast of ocular vessels to show cilio-retinal artery.

(Digested and dissected specimen). $\times 12$.

retinal artery is, however, an end-artery like the true retinal arteries, and it supplies only a localized segment of the retina.

\section{Discussion}

In a general assessment of the findings of an investigation of this type involving an injection method, it is important to recognize the inherent difficulties of the technique, particularly when, as in the present study, the channels to be examined are narrow and lie in a dense connective tissue framework between two main vascular systems.

In the first place, the results are influenced by the efficiency of the injection of Neoprene, and this is dependent not only on the introduction of Neoprene into the circulation in an adequate amount and at a sufficiently high pressure to ensure that even the smallest vessels are filled, but also on the efficiency of the preliminary irrigation of the vessels with water. In this connexion it is interesting to note that Beauvieux and Ristitch (1924), who denied the existence of any branches from the central retinal artery within the optic nerve, used a technique which involved the injection of only $2 \mathrm{ml}$. prussian blue into the central retinal artery without any preliminary irrigation (at least no mention is made in their paper of any preliminary irrigation). It is questionable whether such a technique is sufficiently energetic to reveal the presence of fine inter-vascular connecting links, and it may account for their negative findings.

In the second place, the results are influenced by the ease with which the injected vessels may be exposed to direct view. In the Neoprene casts of the whole ocular circulation there is a vast network of injected vessels, and it is possible to isolate the anastomotic vessels in the optic nervehead only after a prolonged series of dissections involving the removal of many surrounding vessels. The absence of an anastomotic channel in any one specimen may represent, therefore, a failure in technical skill. 
It is felt, therefore, that, because of the technical difficulties outlined above, it is not possible to submit the results of this investigation to a statistical analysis or to give any clear indication of how frequently uveo-retinal arterial anastomoses occur in the healthy eye.

It is a common finding that some time after occlusion of the central retinal artery there is at least a partial restoration of the retinal circulation (Coats, 1905; de Schweinitz and Holloway, 1908; etc.). Coats (1913b) reported a series of six such cases in all of which a complete re-establishment of the retinal circulation took place. There are several possible interpretations of this phenomenon:

(1) The vascular occlusion may be due solely to a spasm of the central retinal artery, so that when the spasm passes off the circulation is restored in the retina. This is the most likely explanation for those cases in which there are transient periods of loss of vision associated with constriction of the retinal arterial circulation.

(2) The vascular occlusion may be due to the lodgement of an embolus within the central retinal artery, and the circulation may be restored at least in part, when the embolus is moved away from the central artery into one of its more peripheral branches, or when the blood is able to pass round the embolus into the peripheral circulation. When an embolus becomes lodged in the central retinal artery there is a spasm of the surrounding arterial wall. The shifting of the embolus to another part of the circulation or the ability of the blood to bypass the embolus presumably results from a decrease in the spasm of the vessel wall.

(3) The vascular occlusion may be due to a thrombosis within the central retinal artery, and the circulation may be restored by canalization of the thrombus. Coats (1905) has suggested also that in certain cases of thrombosis where there is a more rapid re-establishment of some retinal circulation, blood may be forced round a weak area of the thrombus, after a rise in the systemic blood pressure.

Certain cases showing restoration of the retinal circulation do not, however, fit in easily with any of the three mechanisms outlined above; in these the occlusion is too prolonged for pure spasm of the vessel wall, there is no evidence of any embolic focus, or there is histological proof of the permanence of the thrombosis without any attempt at canalization (Coats, 1923a). The most likely mechanism in such cases is the re-establishment of the circulation in the retina through uveo-retinal arterial anastomoses in the optic nervehead.

The establishment of a collateral circulation was suggested by Lawson (1898), and also by Coats (1905) who emphasized the capillary nature of the anastomotic channels so that, although the circulation is restored in the retina, the retinal arteries do not return to their original calibre but remain narrow as an adaptation to a diminished blood flow. Even Beauvieux and Ristitch (1924), who denied the existence of a collateral circulation between the retinal and uveal arteries, considered that the opening up of the retinal 
circulation after occlusion of the central artery must be due, in certain cases, to the existence of some pre-formed channel. This would appear to be a contradiction of their main conclusion.

It has been shown in this present investigation that without doubt uveoretinal arterial anastomoses exist in a certain number of normal eyes, although, for the reasons outlined at the beginning of this discussion, it is difficult to assess the frequency of such anastomoses. On the other hand, in spite of the existence of these collateral channels and in spite of the other mechanisms by which an arterial block may be overcome, the visual prognosis after occlusion of the central retinal artery is extremely poor.

Coats (1905) has suggested that in such cases the block must have occurred so far forward that it lay on the distal side of the collateral circulation, but this is not a likely explanation because there are collateral channels between the central retinal artery and the circle of Zinn quite far forward in the optic nervehead, and because the commonest site for the occluding process in the central retinal artery is in the retro-laminar region (Verhoeff, 1908). Behr (1935) stated that, from the standpoint of the restoration of the retinal circulation, it does not matter where the blockage occurs within the artery, but no emphasis can be placed on this conclusion because it was based on a denial of the existence of any uveo-retinal arterial anastomoses within the optic nerve. It is probably more reasonable to assume that the poor visual prognosis in blockage of the central retinal artery is related to the rapid degeneration of the inner retinal layers which follows any disturbance of the retinal circulation, so that the ganglion cells of the retina have suffered permanent damage before the function of the retinal arteries is restored to an adequate level. Some cases have been reported in which there was a gradual improvement of vision over a period of several days; for example, de Schweinitz and Holloway (1908) gave details of a case in which vision was reduced to a vague perception of light after the occlusion, with a restoration to $6 / 60$ within 40 minutes, and a further gradual improvement to 6/9 within 4 days. It is not clear, however, whether this represents a gradual re-opening of the retinal circulation with a similarly gradual restoration of retinal function, or whether the initial recovery from perception of light to $6 / 60$ represents a re-establishment of retinal circulation, and the subsequent improvement in vision represents a subjective adaptation to the presence of some paracentral visual disturbance, probably in association with a subsidence of oedema of the central retina. The presence of a paracentral scotoma, although perhaps minimal in size, is indicated by the failure of the vision to reach an absolutely normal level. If this is the correct interpretation of the case, then it is an indication of how rapidly damage can occur to the integrity of the retina even when there is a fairly quick restoration of the circulation.

It -is difficult, therefore, to arrive at a definite conclusion regarding the frequency and nature of uveo-retinal arterial anastomoses in the optic nerve- 
head from a study of the events which follow occlusion of the central retinal artery, and the poor visual prognosis may reflect the rapidity of retinal degeneration rather than the poverty of such anastomoses. Of course, some of the cases in which vision is fully and rapidly restored after occlusion of the artery, and which are generally attributed purely to arterial spasm, may, in fact, be cases of true blockage, in which there is a well-marked collateral circulation capable of maintaining an adequate level of retinal nutrition within a short time of the occlusion of the main trunk.

In any case, the known existence of uveo-retinal arterial anastomotic channels in even a few eyes warrants the use of any measure which will promote vaso-dilatation and thus facilitate the opening up of a collateral circulation. These include such procedures as the retrobulbar injection of acetylcholine, and the sudden lowering of the intra-ocular pressure by paracentesis of the anterior chamber.

It is interesting to speculate on what might happen to the vision in cases of central retinal artery occlusion if they were maintained for a short time in an atmosphere rich in oxygen. It has been shown by Ashton, Ward, and Serpell (1954) that in new-born kittens subjected to high oxygen levels the integrity of the retinal function is unimpaired despite the disappearance of the retinal vessels. If in cases of occlusion of the central retinal artery the function of the retina could be maintained by supplemental oxygen until the retinal circulation became restored by the opening up of collateral channels, it might greatly alter the prognosis, provided, of course, that the oxygen therapy was initiated soon enough before the onset of irreparable retinal damage.

It is known that an increase in the concentration of oxygen within the alveolar air gives rise to an increase in the normal arterial oxygen tension (A.M.A., "Fundamentals of Anaesthesia", 1954), and that as a result there is a slight rise in the oxygen tension within the tissues (Campbell, 1927). Furthermore, it has been shown by Cusick, Benson, and Boothby (1940) that the administration of pure oxygen for 30 minutes produces a measurable effect on the calibre and colour of the retinal vessels.

It is not known, however, to what extent this supplemental oxygen will be able to combat the stagnant type of anoxia found within the inner retinal layers as a result of the temporary failure of the retinal arterial circulation, but at the present time it would appear reasonable to put forward the hypothesis that there may be a place for oxygen therapy in the treatment of early cases of occlusion of the central retinal artery. In this connexion a short case note is included below as an appendix.

\section{Summary}

Neoprene casts of the ocular circulation of seventeen normal human eyes were prepared by the injection of Neoprene latex into the ophthalmic artery and the digestion of the ocular tissues in pepsin and trypsin. Each cast was 
dissected to reveal the minute details of the vessels in and around the optic nerve.

Several branches arise from the central retinal artery within the optic nerve and they may form two types of uveo-retinal arterial anastomoses. First, there are anastomoses between the central retinal artery and the arterial plexus of the pia mater surrounding the anterior part of the optic nerve, and, secondly, anastomoses between the central retinal artery and the intrascleral circle of Zinn. These anastomoses are important in a consideration of the pathological events which may follow occlusion of the central retinal artery, and in the consideration of the treatment of such cases. It is suggested that the prompt administration of oxygen may enable some of the retinal ganglion cells to survive the period when the retinal circulation is at an inadequate level, before the re-establishment of the circulation by a collateral channel.

This investigation has been carried out in the Department of Pathology at the Institute of Ophthalmology during the tenure of a Moorfields Research Scholarship and I am most grateful to Dr. Norman Ashton, Director of the Department, for his encouragement and advice throughout the investigation. I am also indebted to Messrs. G. Knight and A. McNeil and to the Medical Illustration Department at the Institute of Ophthalmology for their help in the preparation of the specimens and photographs.

\section{REFERENCES}

American Medical Association (1954). “ “Fundamentals of Anaesthesia ”, 3rd. ed., p. 1. AsHTON, N. (1951). British Journal of Ophthalmology, 35, 291. (1952). Ibid., 36, 465.

- W WARD, B., and SERPELL, G. (1954). Ibid., 38, 397.

BeauvieuX, J., and Ristitch, K. (1924). Arch. Ophtal., 41, 352.

BeHR, C. (1935). v. Graefes Arch. Ophthal., 134, 227.

Bignell, J. L. (1952). Trans. ophthal. Soc. Austr., 12, 105.

CAMPBell, J. A. (1927). J. Physiol. (Lond.), 62, 211.

CoATs, G. (1905). Roy. Lond. ophthal. Hosp. Rep., 16, 262.

(1913a). Ibid., 19, 45. (1913b). Ibid., 19, 71 . (1913c). Trans. ophthal. Soc. U.K., 33, 30.

Cusick, P. L., Benson, O. O., and Boothby, W. M. (1940). Proc. Mayo Clin., 15, 500.

François, J., and NeETENS, A. (1954). British Journal of Ophthalmology, 38, 472.

- and ColletTE, J. M. (1955). Ibid., 39, 220.

GonIN, J. (1905). Ann. Oculist. (Paris), 133, 167.

LANG, W., and BARReTt, J. W. (1888). Rov. Lond. ophthal. Hosp. Rep., 12, 59.

LAWSON, A. (1898). Trans. ophthal. Soc. U.K., 18, 148.

LEBER, T. (1903). In "Graefe-Saemisch Handbuch der gesamten Augenheilkunde ", 2nd. ed., Bd. 2, Abt. 2. Engelmann, Leipzig.

Magitor, A. (1908). Thèse de Paris. Vigot Frères, Paris.

Michaelson, I. C. (1951). "XVI Concilium ophthalmologicum, 1950, Britannia Acta", vol. 1., p. 605 . B.M.A., London.

MoffaT, D. B. (1952). J. Anat. (Lond.), 86, 490.

NeTtLeship, E. (1876). Brit. med.J., 1, 161. (1877). Roy. Lond. ophthal. Hosp. Rep., 9, 161.

Parsons, J. H. (1906). "The Pathology of the Eye", vol. 3, p. 950. Hodder and Stoughton, London.

Randall, B. A. (1887). Trans. Amer. ophthal. Soc., 4, 511.

SAUTter, H., and Seitz, R. (1952). v. Graefes Arch. Ophthal., 152, 413.

Schweinitz, G. E. DE, and Holloway, T. B. (1908). Trans. Amer. ophthal. Soc., $11,471$.

VERHOEFF, F. H. (1908). Ibid., 11, 416.

WolfF, E. (1938). Trans. ophthal. Soc. U.K., 58, 70. (1939). Ibid., 59, 157. 
WolfF, E. (1948). “ The Anatomy of the Eye and Orbit", 3rd. ed., p. 310. Lewis, London. WYBAR, K. C. (1954a). British Journal of Ophthalmology, 38, 513. (1954b). “ XVII Concilium ophthalmologicum 1954, New York". (In press).

\section{APPENDIX}

This report concerns the administration of oxygen in a case of occlusion of the central retinal artery of the left eye.

\section{Case Report}

A man aged 70 years developed an occlusion of the central retinal artery of the right eye in 1952 with practically total loss of vision in that eye. At the present time there is only a vague awareness of light within a narrow zone in the temporal periphery of the right visual field. The right optic disc is pale but, apart from moderate hypertensive changes, there is no attenuation of the retinal arteries.

Until March 11, 1955, the vision of the left eye had been good, but suddenly at 8 a.m. on that day his sight became cloudy and within a few minutes he could only distinguish vague outlines of objects. He was examined at the Middlesex Hospital at 11 a.m. when his vision was limited to hand movements. The retinal arteries of the left eye were markedly attenuated and there was some oedema of the central part of the fundus. An occlusion of the central retinal artery was diagnosed.

Therapy.-Shortly after mid-day the patient was placed in an oxygen tent where an atmosphere of 70 per cent. oxygen concentration was obtained with a flow of 7 litres of oxygen per min. This was maintained for the following $72 \mathrm{hrs}$. He was also given $50 \mathrm{mg}$. nicotinic acid four times daily.

Result.-On removal from the oxygen tent he was able to count fingers easily, and, a few days later, when it was possible to record his vision more accurately, he could read $6 / 60$ corrected to $6 / 24(-1)$. His reading vision with a presbyopic addition was N 24, but within a few days this improved to $\mathrm{N} 6$ although only with great difficulty. Since then his distant vision has fluctuated between $6 / 24$ and 6/18, and his reading vision between $N 24$ and N 6 . The visual field has remained fairly constant with a peripheral limit of about $30^{\circ}$ as recorded on the perimeter with a 3-mm. white test object, and there are also vague areas of relative loss in the paracentral area.

Conclusion.-There is no doubt that the ganglion cells of the retina of the left eye have suffered a considerable degree of permanent damage with complete involvement of parts of the peripheral retina and scattered involvement of the central retina. It is the implication of the central retina which accounts for the variability of the vision, and for the great difficulty which is experienced on attempting to read small print. On the other hand, when account is taken of the poor vision which usually follows occlusion of the central retinal artery and of the practically total loss of sight in the right eye after a similar central retinal arterial occlusion, the visual result must be regarded as satisfactory.

There is, of course, no direct evidence that the administration of oxygen affected the result in any way, and it is quite possible to regard the improvement in vision solely as a spontaneous occurrence. In view, however, of the hypothesis which has been put forward in the preceding paper it is hoped that oxygen therapy will be tried in similar early cases.

My thanks are due to Mr. D. Ainslie who kindly admitted the patient to the Middlesex Hospital for this clinical trial. 